\title{
Preparation and Characterization of Natural Zeolite Modified with Iron Nanoparticles
}

\author{
Alvaro Ruíz-Baltazar, ${ }^{1}$ Rodrigo Esparza, ${ }^{1}$ Maykel Gonzalez, \\ Gerardo Rosas, ${ }^{2}$ and Ramiro Pérez ${ }^{1}$ \\ ${ }^{1}$ Center for Applied Physics and Advanced Technology, National Autonomous University of Mexico, Boulevard Juriquilla 3001, \\ 76230 Santiago de Querétaro, QRO, Mexico \\ ${ }^{2}$ Metallurgical Research Institute, UMSNH, Ciudad Universitaria, Edificio U, 58000 Morelia, MICH, Mexico
}

Correspondence should be addressed to Alvaro Ruíz-Baltazar; alvarodejesusruiz@yahoo.com.mx

Received 1 May 2015; Accepted 10 August 2015

Academic Editor: Xuping Sun

Copyright (C) 2015 Alvaro Ruíz-Baltazar et al. This is an open access article distributed under the Creative Commons Attribution License, which permits unrestricted use, distribution, and reproduction in any medium, provided the original work is properly cited.

\begin{abstract}
This study is aimed at investigating the structural and morphological characterization of natural and modified zeolite obtained from the state of Oaxaca (Mexico). Iron nanoparticles were used for the zeolite modification. The iron nanoparticles were loaded on the zeolite surface by homogeneous nucleation. Adsorption kinetic models of pseudo first and second order were surveyed. The characterization of pristine and modified zeolite was performed by Fourier transform infrared (FTIR), transmission electron microscopy (TEM), and X-ray diffraction (XRD). From the results, three main phases were identified: clinoptilolite, mordenite, and feldspar. We could also determine the adsorption capacity of the zeolites by means of adsorption kinetic models.
\end{abstract}

\section{Introduction}

The natural zeolites, specifically, the clinoptilolite, have been widely studied due to the great cationic exchange capacity presented and their potential applications in the removal of pathogenic microorganisms [1-5]. The zeolites are highly porous with cavities in their structure with pore sizes and characteristic chemical composition [6]. Recent researches showed the bactericide effect of the Mexican zeolites modified with silver ions in the treatment of wastewater [79]. Additionally, the Mexican zeolites were evaluated in adsorption of the contaminant as the phenol and ions of Cs, As, $\mathrm{Cd}, \mathrm{Mn}, \mathrm{Fe}, \mathrm{Hg}, \mathrm{Ni}$, and $\mathrm{Pb}$ in aqueous solutions [9-12]. However, the internal surface area and pore size distribution determine the efficiency in the adsorption process. In recent years, natural zeolites have been used in removing organic compounds and nonpolar species [13-15]. This is due to the hydrophilic nature of the zeolite surface [16-18]. For this reason, the investigation of physical changes of natural zeolites offers new possibilities of applications. The purpose of this research is to characterize structurally the modified clinoptilolite with iron nanoparticles using TEM technique and describe the adsorption mechanism of Fe nanoparticles through an adsorption kinetics study of natural zeolite from Oaxaca State $\left(97^{\circ} 13^{\prime}\right.$ O y $\left.17^{\circ} 14^{\prime}\right)$.

\section{Materials and Methods}

For this study, a zeolite from Oaxaca was employed. The mineral was milled and sieved to $-120+60$ mesh $(2 \mathrm{~mm})$. A washing treatment was conducted on the material by magnetic stirring at $700 \mathrm{rpm}$ for a period of $60 \mathrm{~min}$. Subsequently, the material was dried at a temperature of $40^{\circ} \mathrm{C}$ for $24 \mathrm{hrs}$. Fe nanoparticles were initially synthesized by chemical reduction method starting from $\mathrm{Fe}_{2} \mathrm{Cl}_{3}$ with sodium borohydride and stabilized with PVP. Afterwards, $1 \mathrm{~g}$ of zeolite was mixed with $1 \mathrm{~mL}$ of nanoparticles at different concentrations $\left(1,3,5,7\right.$, and $\left.10 \mathrm{mgL}^{-1}\right)$. The mixture was magnetic stirring $(300 \mathrm{rpm})$ in intervals of $30 \mathrm{~min}$ from 0 to $180 \mathrm{~min}$. The identification of the crystalline phases of the sample was performed by X-ray diffraction using a Siemens diffractometer for powders polycrystalline model D5000 fitted with a scintillation counter with a $\mathrm{CuK} \alpha$ radiation 


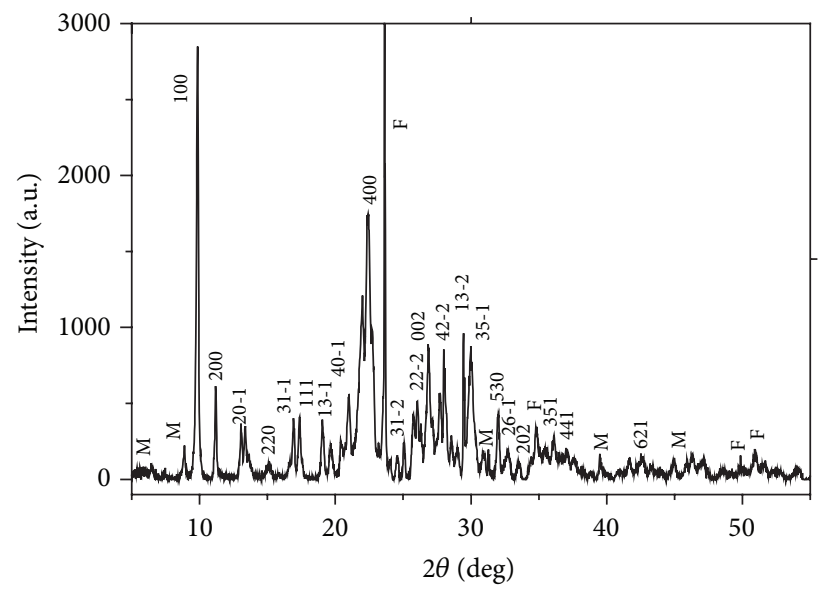

FIGURE 1: XRD pattern corresponding to the Mexican zeolite with three principal phases identified (clinoptilolite, mordenite, and feldspars).

and monochromator. The power used was $20 \mathrm{~mA}$ and $30 \mathrm{kV}$. The conditions of the obtained diffraction spectra were 8 seconds per step $0.02^{\circ}$. The structural and morphological characteristics zeolite was studied using a Philips Tecnai F20 transmission electron microscope with a field-emission gun attachment.

\section{Results and Discussion}

\subsection{Materials Characterization}

3.1.1. X-Ray Diffraction Analysis. Figure 1 shows the pattern of X-ray diffraction carried out to natural zeolite, in which different mineralogical phases are observed. The main observed phase is clinoptilolite, which is highlighted by their respective miller indices. Mordenite (M) phase was also identified in the spectrum and feldspars phase $(F)$ in a smaller proportion.

3.1.2. Transmission Electron Microscopy. For the structural characterization of the different morphologies observed in the natural zeolite, the technique of transmission electron microscopy was employed. Figure 2(a) shows a bright field TEM image corresponding to the Mexican zeolite, in which the presence of different phases can be observed. The study evidenced three main morphologies. Figure 2(b) indicates the presence of the clinoptilolite phase with a typical hexagonal morphology. In the case of mordenite, Figure 2(c) describes the needle-like morphology corresponding to this mineralogical phase. Finally, the morphology associated with the feldspar is shown in Figure 2(d) in which granular aggregates with no defined morphologies can be noticed.

In order to associate the different morphologies observed in the natural zeolite with their mineralogical phases, HRTEM analysis was carried out. Figure 3(a) shows the clinoptilolite phase associated with the faceted morphologies, in which an interplanar distance of $0.512 \mathrm{~nm}$ corresponding to planes (111) of the monoclinic structure of clinoptilolite with the following red parameters was found: $a=17.65 \AA$, $b=17.92 \AA, c=7.403 \AA$, and $\beta=116.39^{\circ}$ (89-7539).
In Figure 3(b), a selected area electron diffraction (SAED) pattern of the clinoptilolite phase is presented in the axis zone $[\overline{1} 2 \overline{1}]$. HRTEM analysis of the mordenite is presented in Figure 3(c). A $d$-spacing distance of $0.415 \mathrm{~nm}$ was measured; this interplanar distance is corresponding to planes (420). The SAED pattern of the mordenite in the [234] axis zone is presented in Figure 3(d). The minority phase of feldspar was also identified by high resolution analysis (Figure 3(e)). In this study, an interplanar distance of $0.22 \mathrm{~nm}$ was measured and associated with the monoclinic structure of feldspar. This analysis is complemented by electron diffraction pattern obtained from the feldspar (Figure 3(f)), in which planes (132) and $(\overline{3} 12)$ corresponding to the zone axis [2 $\overline{4} 5]$ are observed.

Figures 4(a)-4(d) show an image transmission electron microscopy at low magnifications of composite nanoparticles of iron and zeolite. From this image, it can be observed that the nanoparticles are effectively accommodated in the surface of the zeolite. On the other hand, the nanoparticles are attached to each other, given the large surface area and magnetic nature by the metal particles. The results obtained in the adsorption kinetic model are supported and verified by TEM image.

3.1.3. Infrared Spectroscopy. FT-IR spectra of the natural zeolite are shown in Figure 5, in which it can be observed that the band associated with the symmetric and asymmetric stretching vibrations of the hydroxyl functional group is situated at $3614 \mathrm{~cm}^{-1}[19,20]$. Additionally, the band located at $1645 \mathrm{~cm}^{-1}$ is due to the vibration of the bond $\mathrm{Si}-\mathrm{O}$. The generated vibrations by $\mathrm{Al}-\mathrm{O}$ bonds are described by the intensity located at $1087 \mathrm{~cm}^{-1}$ [21]. The allotropic phase of $\mathrm{SiO}_{2}$ is identified by the intensity observed in $797 \mathrm{~cm}^{-1}$. It is important to mention that the intensities associated with the $\mathrm{Si}-\mathrm{O}$ and $\mathrm{O}-\mathrm{Al}$ bonds, which is typical of tectosilicates, are very strong, which suggests that the zeolite has a large surface area.

3.2. Iron Nanoparticles Adsorption: Experimental Behavior. In order to determine the amount of $\mathrm{Fe}^{0}$ nanoparticles adsorbed 


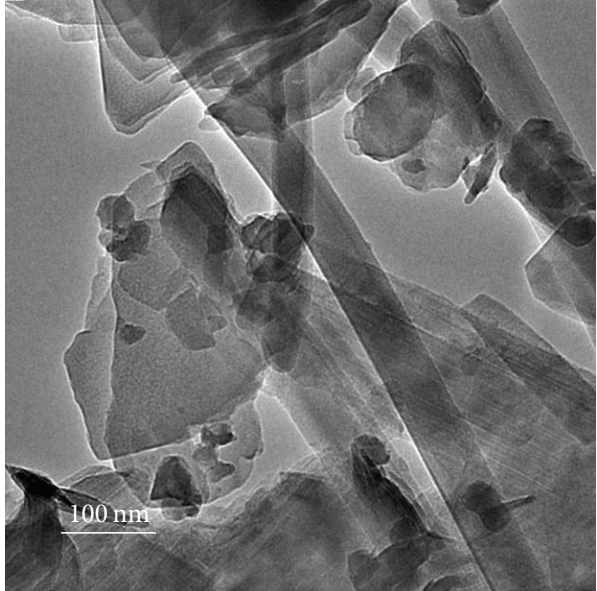

(a)

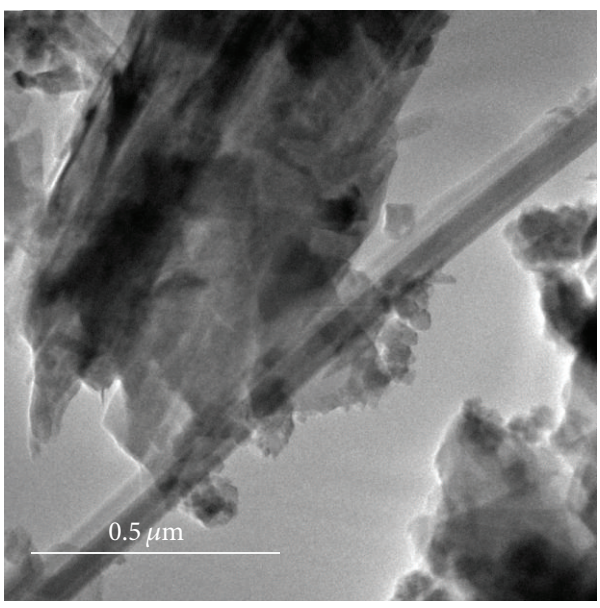

(c)

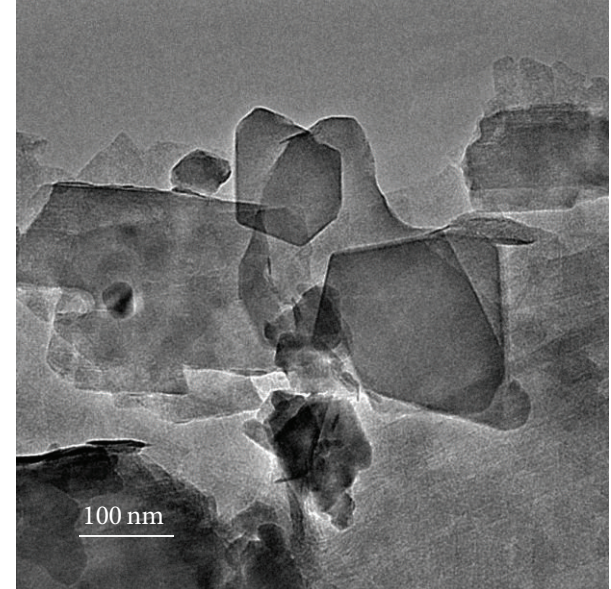

(b)

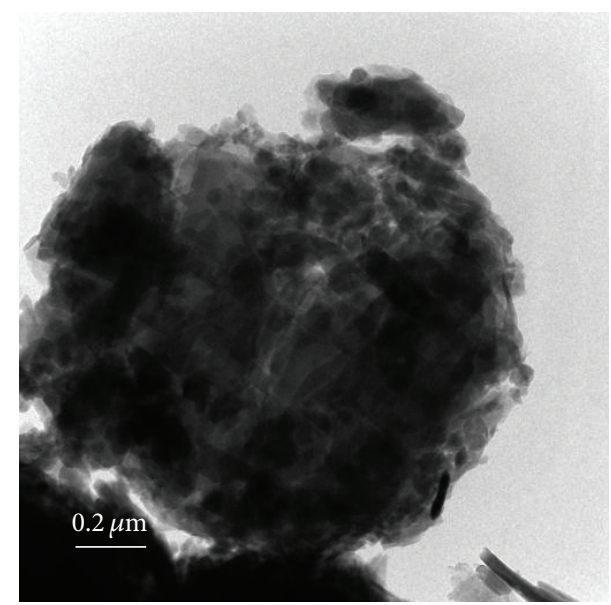

(d)

FIGURE 2: (a) Bright field TEM image corresponding to the Mexican zeolite, (b) clinoptilolite phase, (c) mordenite, and (d) feldspars.

on the zeolite, analysis by atomic absorption spectrophotometry was performed. The final concentrations of $\mathrm{Fe}^{0}$ nanoparticles, measured after the direct impregnation on the natural zeolite, were used to describe experimentally the $\mathrm{Fe}^{0}$ adsorption process into the porous material.

Figure 6(a) shows a graph of the mixture of iron and zeolite nanoparticles without magnetic stirring. In this case, the sample was only centrifuged. This experiment was carried out for different concentrations of nanoparticles in the range 1$10 \mathrm{mgL}^{-1}$. It is of note that the highest amount of $\mathrm{Fe}^{0}$ particles adsorbed by the zeolite is $5 \mathrm{mgL}^{-1}$, which corresponds to the equilibrium concentration. Subsequently, the amount of iron nanoparticles adsorbed by the zeolite as a function of time of magnetic stirring was evaluated. In this procedure, the sample of $5 \mathrm{mgL}^{-1}$ was used because this concentration showed the highest adsorption.

Figure 6(b) describes the adsorption behavior presented by the sample of $5 \mathrm{mgL}^{-1}$ at different agitation times. As a result of this procedure, the equilibrium time necessary in this adsorption process was determined. We determined that about 180 minutes was required to conduct the greatest adsorption of Fe nanoparticles, whose value is around 95\%. Finally, to verify this fact, Figure 6(c) shows the adsorption behavior of all samples $(1,3,5,7$, and $10 \mathrm{ppm})$ at different times of magnetic stirring. This graph clearly shows that the adsorption is independent of time and greatest adsorption can always be attributed to the sample of $5 \mathrm{mg} / \mathrm{L}$ concentration.

3.3. Adsorption Kinetics: Theoretical Models. The theoretical models revel the solid/liquid adsorption processes. These processes are generally due to a cation exchange reaction between adsorbent and adsorbate related to a mass-transport processes or particles diffusion in macropores or micropores [22]. Lagergren pseudo first and pseudo second order models are proposed in order to describe and verify the kinetic behavior observed experimentally by the iron nanoparticles.

3.3.1. Lagergren Pseudo First Order Model. To determine the adsorption capacity of the zeolite adsorption kinetic models of pseudo first and second order are used. The kinetic 


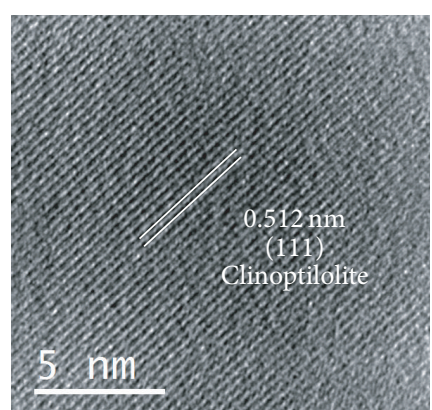

(a)

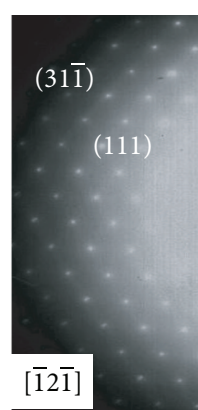

(b)

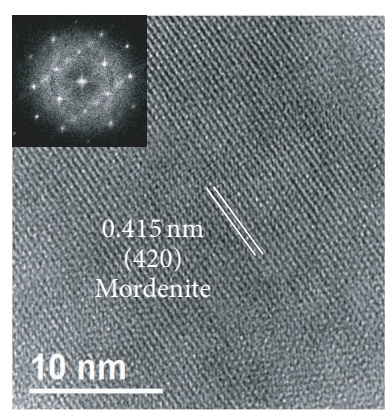

(c)

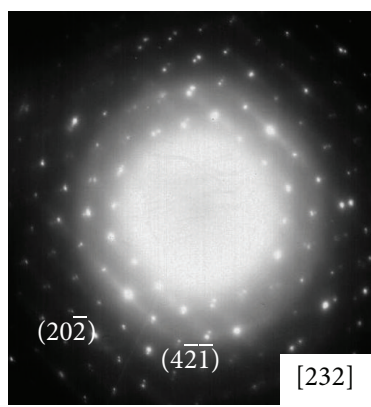

(d)

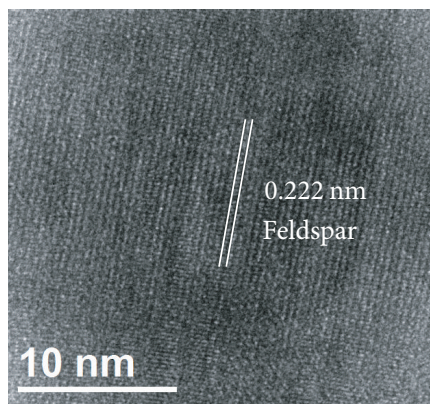

(e)

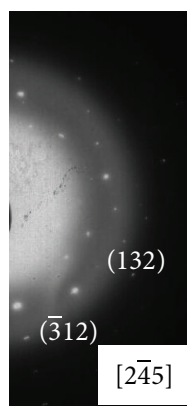

(f)

FIGURE 3: HRTEM image and SAED pattern corresponding to (a-b) clinoptilolite, (c-d) mordenite, and (e-f) feldspars phase.

TABLE 1: Parameters kinetic models of pseudo first order and pseudo second order of the iron nanoparticles in zeolite.

\begin{tabular}{lccccc}
\hline & & Lagergren model & \multicolumn{2}{c}{ Pseudo second order model } \\
& $K_{1}(\mathrm{~min})^{-1}$ & $R^{2}$ & $\Delta q(\%)$ & $K_{2}(\mathrm{~g} \mathrm{~min} / \mathrm{mg})$ & 0.26250836 \\
$3 \mathrm{ppm}$ & $1.61 E-03$ & 0.97898 & 3.41886903 & 0.018532 & 0.96305 \\
$3 \mathrm{ppm}$ & $9.63 E-03$ & 0.95897 & 37.2484767 & 0.00766253 & 0.92494 \\
$5 \mathrm{ppm}$ & $2.34 E-02$ & 0.98392 & 57.8103046 & 0.0066116 & 0.93407 \\
$7 \mathrm{ppm}$ & $2.37 E-02$ & 0.93473 & 37.6276312 & 0.00451299 & 0.94468 \\
$10 \mathrm{ppm}$ & $2.33 E-02$ & 0.95435 & 121.628273 & \\
\hline
\end{tabular}

model of pseudo first order is determined by the equation of Lagergren [22]:

$$
\frac{d q}{d t}=K_{1}\left(q_{e}-q_{t}\right)
$$

where $k_{1}\left(\mathrm{~min}^{-1}\right)$ is the pseudo first order adsorption rate coefficient. Integrating (1) and using the boundary conditions $t=0, q_{t}=0, t=t$, and $q_{t}=q_{t}$,

$$
\ln \left(q_{e}-q_{t}\right)=\ln q_{e}-k t,
$$

where $q_{e}$ and $q_{t}$ are the values of the amount adsorbed per unit mass at equilibrium and at any time $t$, respectively. The linear plot of $\ln \left(q_{e}-q_{t}\right)$ versus $t$ determines the values of $k_{1}$ and $\ln q_{e} . k_{1}$ values and the correlation coefficient $R^{2}$ are presented in Table 1.

Figure 7 shows the pseudo first order kinetic model, from the zeolite, in which it can be observed that kinetic model reveals a pseudo first order correlation values ranging from 0.95435 to 0.98392 . This result suggested that the kinetic
Lagergren model adjusts significantly mainly to a sample of $5 \mathrm{gL}^{-1}$ in which the correlation factor $\left(R^{2}\right)$ is 0.98392 . For concentrations greater than $5 \mathrm{ppm}$, the correlation factors decreased. This indicated that the maximum capacity for adsorption of nanoparticles is presented with the sample of $5 \mathrm{gL}^{-1}$. After this concentration, the zeolite does not adsorb more nanoparticles. It was concluded that one gram of zeolite is capable of adsorbing $4.75 \mathrm{gL}^{-1} \mathrm{Fe}$ nanoparticles. Additionally, the highest values of $k_{1}$ are seen for samples of 5 and $7 \mathrm{gL}^{-1}$, which are similar $\left(0.00234\right.$ and $\left.0.00237 \mathrm{~min}^{-1}\right)$. This result implies that the rate of adsorption also has a maximum value at the concentration of $5 \mathrm{gL}^{-1}$.

3.3.2. Pseudo Second Order Model. The kinetic adsorption model of pseudo second order is defined by the equation $[23,24]$

$$
\frac{d q}{d t}=K_{2}\left(q_{e}-q_{t}\right)^{2}
$$




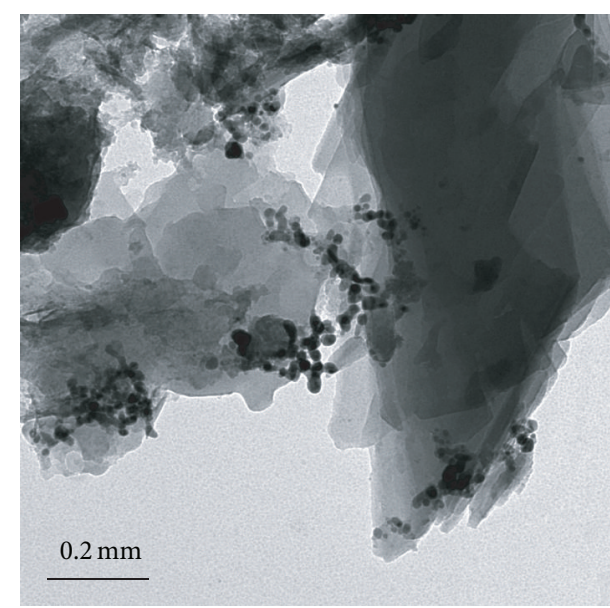

(a)

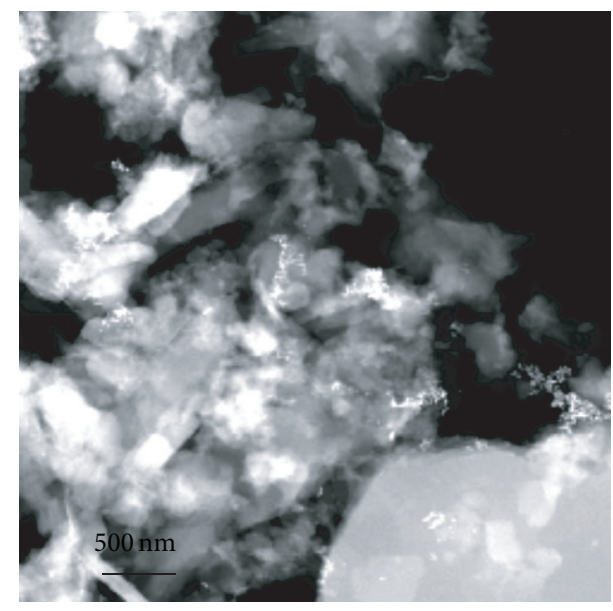

(c)

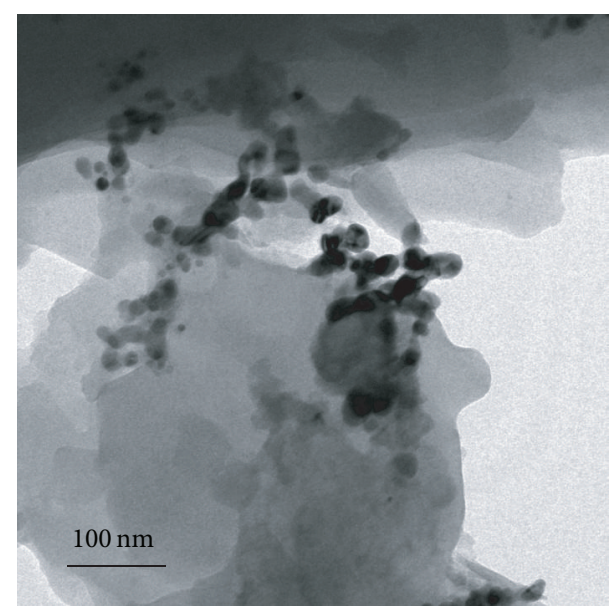

(b)

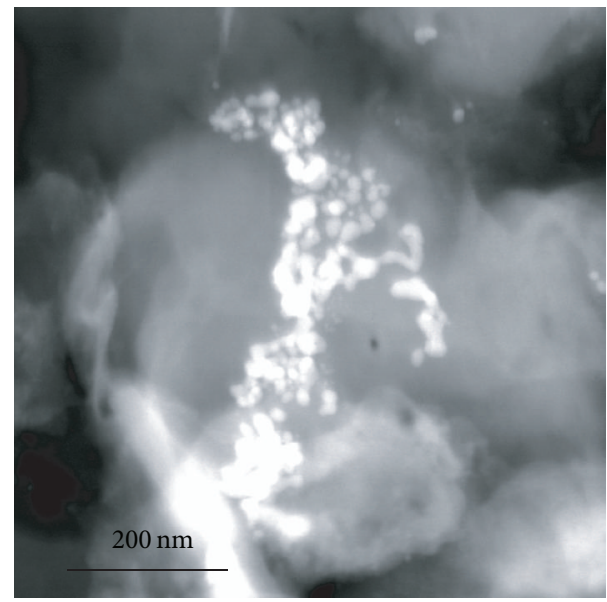

(d)

FIgURE 4: (a-d) Bright field TEM image of Fe nanoparticles physisorbed on the zeolite surface.

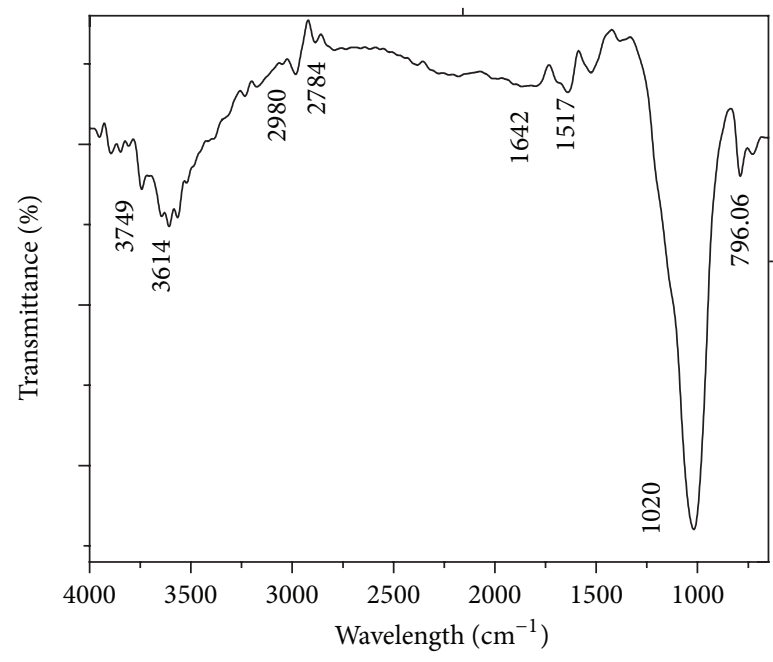

FIGURE 5: FT-IR spectra of the natural zeolite clinoptilolite type. 


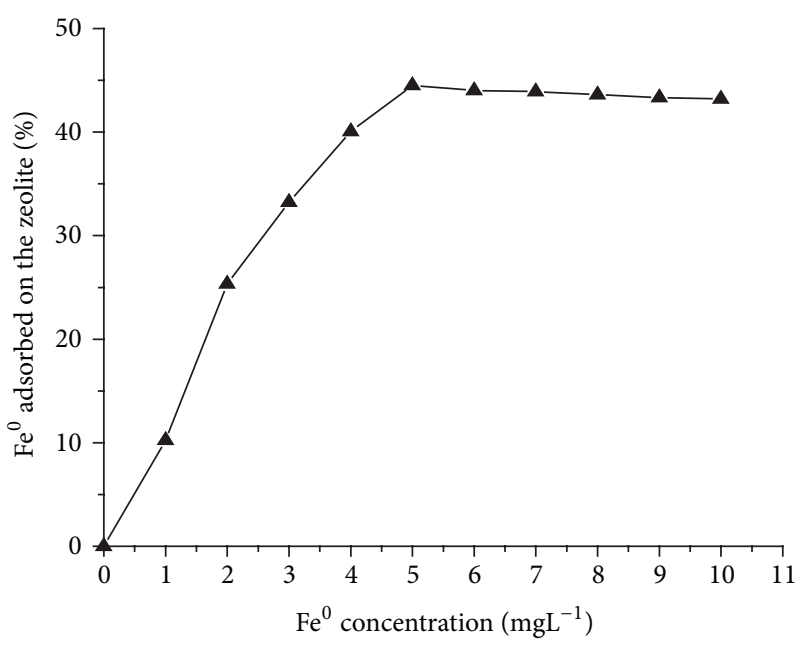

(a)

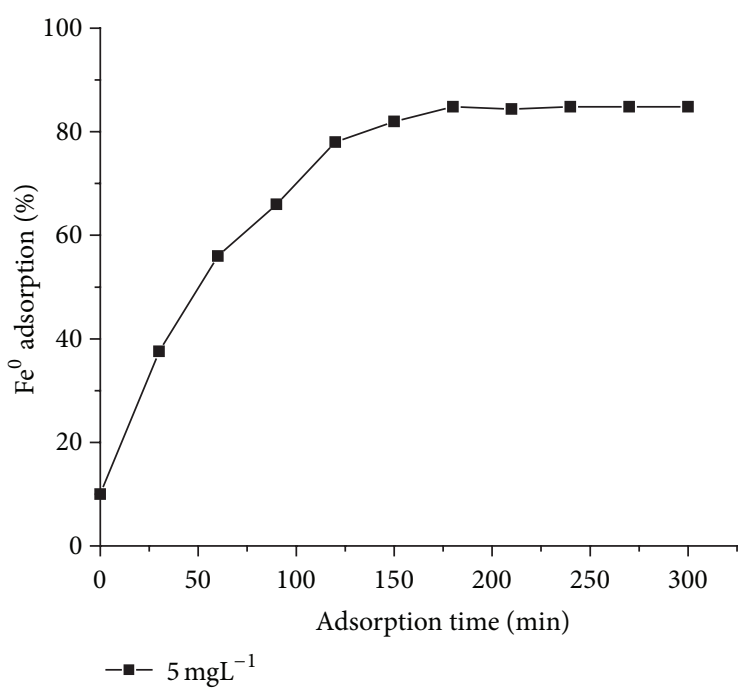

(b)

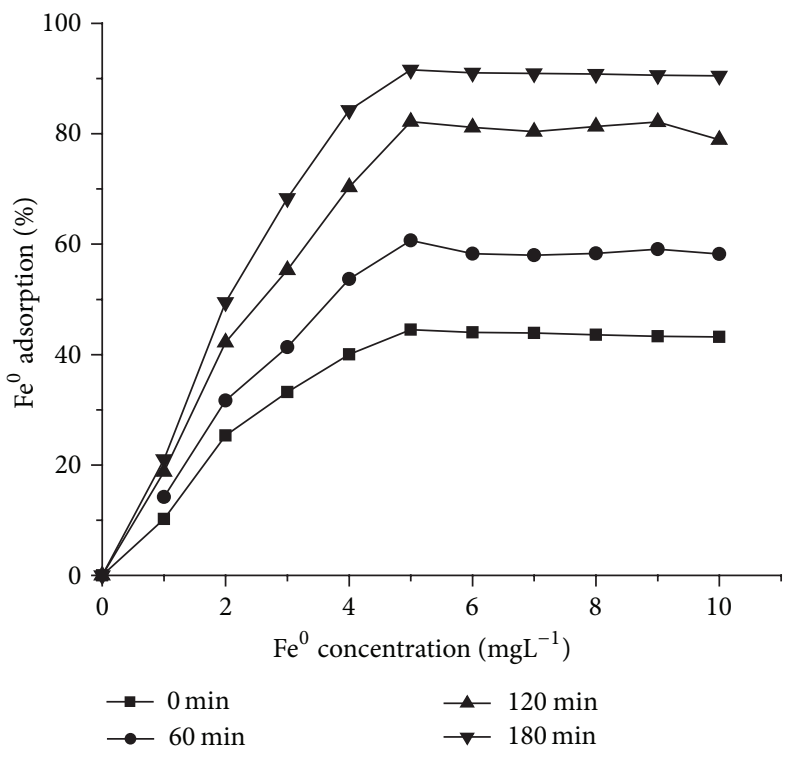

(c)

FIGURE 6: Graphs of Fe adsorption obtained experimentally, (a) without magnetic stirring $(t=0 \mathrm{~min})$, at different stirring times with (b) constant concentration $\left(5 \mathrm{mgL}^{-1}\right)$ and (c) concentrations of $1-10 \mathrm{mgL}^{-1}$.

The solution of this equation is obtained by direct integration using limits $t=0, q_{t}=0, t=t$, and $q_{t}=q_{t}$. Consider

$$
\frac{t}{q_{t}}=\frac{1}{k_{2} q_{e}^{2}}-\frac{1}{q_{e}} t
$$

where $k_{2}$ is the rate constant pseudo second order $\left(\mathrm{g} \mathrm{mg}^{-1} \mathrm{~min}^{-1}\right)$ which describes the amount of nanoparticles adsorbed by the zeolite at time $t$ and at equilibrium, respectively. Figure 8 indicates the pseudo second order model, in which it is observed that, for lower concentrations of $\mathrm{Fe}$ nanoparticles, the adsorption rates are very high and as the concentration of these particles increases, the adsorption rates decrease significantly. This result suggests that lower concentrations of $\mathrm{Fe}$ nanoparticles have greater interaction with the surface area of the zeolite. However, when the concentration increases, the adsorption of these particles is diminished due to the saturation of $\mathrm{Fe}$ in the surface of the zeolite. Nevertheless, $R^{2}$ values indicate lower agreement between experimental values and pseudo second order model. Therefore, Lagergren model describes more accurately the kinetics of adsorption of the nanoparticles of iron in the zeolite.

For this reason, the interaction between the iron nanoparticles and the zeolite is superficial, and a phenomenon physisorption is carried out. On the other hand, the $k_{2}$ values (Table 1) showed that, at lower concentrations of Fe nanoparticles, the adsorption rates are higher; however, in 


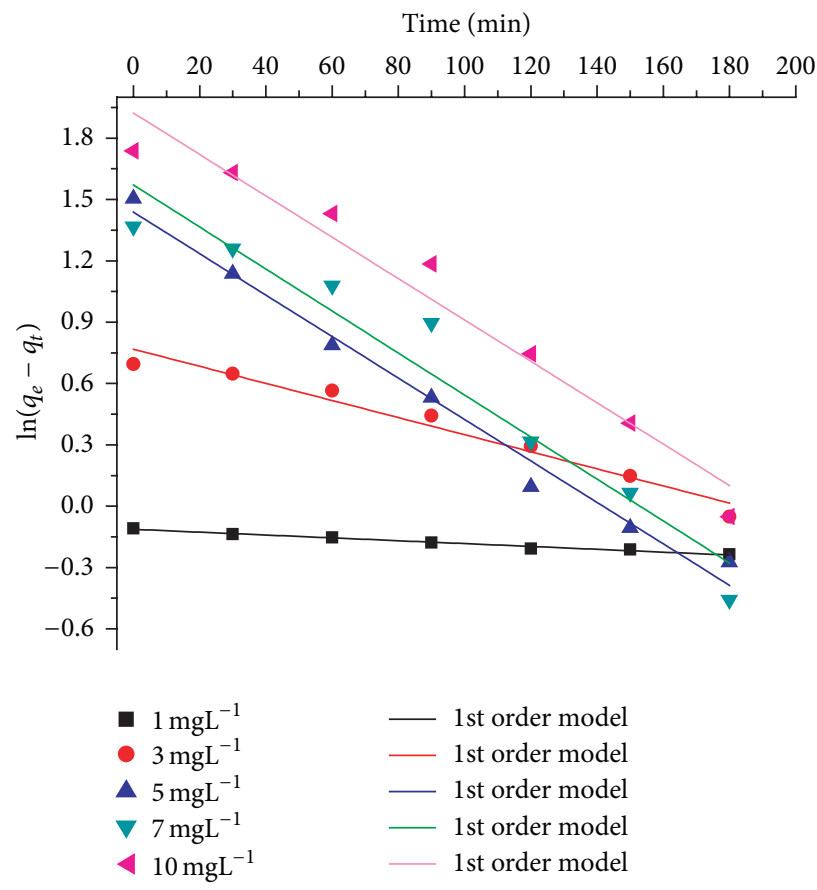

FIGURE 7: Kinetic analysis of the adsorption of zeolite loaded with Fe nanoparticles obtained by Lagergren pseudo first order model.

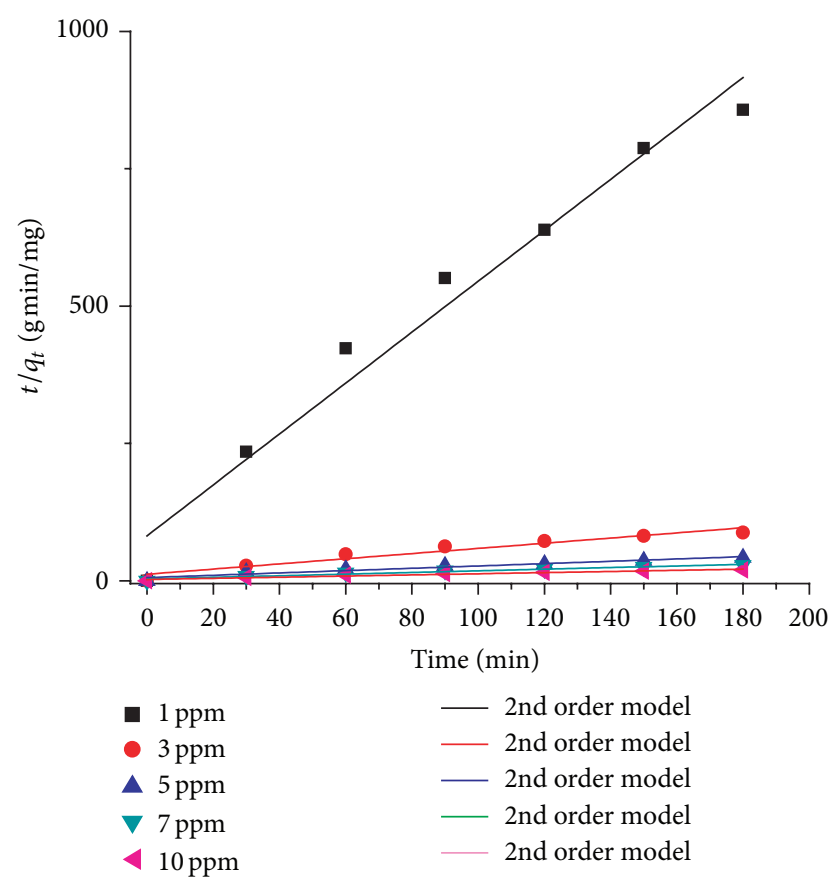

Figure 8: Second order plots for Fe nanoparticles (1, 3, 5, 7, and $10 \mathrm{mgL}^{-1}$ ) adsorbed on natural zeolite.

concentrations greater than $5 \mathrm{ppm}$, the adsorption rate does not present important variations. This result verifies the results obtained by the Lagergren model, where, from 5 ppm, the values $q_{t}$ and $k_{1}$ do not exhibit relevant changes.

\section{Conclusions}

In the structural characterization of the Mexican natural zeolite, the three mineral phases were identified: clinoptilolite, mordenite, and feldspars. We could change the physical properties of zeolite by the addition of iron nanoparticles. Through adsorption kinetic models, the maximum amount of Fe particles adsorbed by the natural zeolite was determined. The concentration and adsorption rates values were clearly identified. Consequently, the obtained experimental values and adsorption kinetic models allowed the evaluation of the adsorption capacity of zeolites, which was of the order $4.75 \mathrm{mg} \mathrm{Fe} / \mathrm{g}$ zeolite. The physisorption phenomenon was observed due to the Lagergren pseudo first order model. This model describes more accurately the experimental values obtained. This fact was confirmed by TEM micrographs, where the accommodation of Fe nanoparticles was on the surface of the zeolite.

\section{Conflict of Interests}

The authors declare that there is no conflict of interests regarding the publication of this paper.

\section{References}

[1] M. Anari-Anaraki and A. Nezamzadeh-Ejhieh, "Modification of an Iranian clinoptilolite nano-particles by hexadecyltrimethyl ammonium cationic surfactant and dithizone for removal of $\mathrm{Pb}$ (II) from aqueous solution," Journal of Colloid and Interface Science, vol. 440, pp. 272-281, 2015. 
[2] K. Barczyk, W. Mozgawa, and M. Król, "Studies of anions sorption on natural zeolites," Spectrochimica Acta Part A: Molecular and Biomolecular Spectroscopy, vol. 133, pp. 876-882, 2014.

[3] R. Cortés-Martínez, M. T. Olguín, and M. Solache-Ríos, "Cesium sorption by clinoptilolite-rich tuffs in batch and fixedbed systems," Desalination, vol. 258, no. 1-3, pp. 164-170, 2010.

[4] I. De la Rosa-Gómez, M. T. Olguín, and D. Alcántara, "Antibacterial behavior of silver-modified clinoptilolite-heulandite rich tuff on coliform microorganisms from wastewater in a column system," Journal of Environmental Management, vol. 88, no. 4, pp. 853-863, 2008.

[5] H. Faghihian, M. Moayed, A. Firooz, and M. Iravani, "Synthesis, characterization, and evaluation of a ferromagnetically modified natural zeolite composite for removal of $\mathrm{Cs}^{+}$and $\mathrm{Sr}^{2+}$," Clays and Clay Minerals, vol. 61, no. 3, pp. 193-203, 2013.

[6] M. Maretto, F. Blanchi, R. Vignola et al., "Microporous and mesoporous materials for the treatment of wastewater produced by petrochemical activities," Journal of Cleaner Production, vol. 77, pp. 22-34, 2014.

[7] E. B. Simsek, E. Özdemir, and U. Beker, "Process optimization for arsenic adsorption onto natural zeolite incorporating metal oxides by response surface methodology," Water, Air, and Soil Pollution, vol. 224, no. 7, pp. 1-14, 2013.

[8] Y. Yu, J. G. Shapter, R. Popelka-Filcoff, J. W. Bennett, and A. V. Ellis, "Copper removal using bio-inspired polydopamine coated natural zeolites," Journal of Hazardous Materials, vol. 273, pp. 174-182, 2014.

[9] M. Rivera-Garza, M. T. Olguín, I. García-Sosa, D. Alcántara, and G. Rodríguez-Fuentes, "Silver supported on natural Mexican zeolite as an antibacterial material," Microporous and Mesoporous Materials, vol. 39, no. 3, pp. 431-444, 2000.

[10] F. Chávez-Rivas, G. Rodríguez-Fuentes, G. Berlier et al., "Evidence for controlled insertion of Fe ions in the framework of clinoptilolite natural zeolites," Microporous and Mesoporous Materials, vol. 167, pp. 76-81, 2013.

[11] A. Ruíz-Baltazar, R. Esparza, R. Pérez, and G. Rosas, "Synthesis of Ag nanoparticles-clinoptilolite composite by homogeneous and heterogeneous nucleation," Materials Science Forum, vol. 755, pp. 97-103, 2013.

[12] C. Díaz-Nava, M. T. Olguín, M. Solache-Ríos, M. T. AlarcónHerrera, and A. Aguilar-Elguezabal, "Phenol sorption on surfactant-modified Mexican zeolitic-rich tuff in batch and continuous systems," Journal of Hazardous Materials, vol. 167, no. 1-3, pp. 1063-1069, 2009.

[13] J. F. Román-Zamorano, M. Flores-Acosta, H. Arizpe-Chávez, F. F. Castillón-Barraza, M. H. Farías, and R. Ramírez-Bon, "Structure and properties of lead and lead sulfide nanoparticles in natural zeolite," Journal of Materials Science, vol. 44, no. 18, pp. 4781-4788, 2009.

[14] E. B. Simsek, E. Özdemir, and U. Beker, "Process optimization for arsenic adsorption onto natural zeolite incorporating metal oxides by response surface methodology," Water, Air, and Soil Pollution, vol. 224, no. 7, article 1614, 2013.

[15] C. Orha, A. Pop, C. Lazau, I. Grozescu, V. Tiponut, and F. Manea, "Structural characterization and the sorption properties of the natural and synthetic zeolite," Journal of Optoelectronics and Advanced Materials, vol. 13, no. 5, pp. 544-549, 2011.

[16] A. Nezamzadeh-Ejhieh and M. Amiri, "CuO supported Clinoptilolite towards solar photocatalytic degradation of p-aminophenol," Powder Technology, vol. 235, pp. 279-288, 2013.
[17] G. Narin, Ç. B. Albayrak, and S. Ülkü, "Antibacterial and bactericidal activity of nitric oxide-releasing natural zeolite," Applied Clay Science, vol. 50, no. 4, pp. 560-568, 2010.

[18] D. Humelnicu, M. V. Dinu, and E. S. Drăgan, "Adsorption characteristics of $\mathrm{UO}_{2}^{2+}$ and $\mathrm{Th}^{4+}$ ions from simulated radioactive solutions onto chitosan/clinoptilolite sorbents," Journal of Hazardous Materials, vol. 185, no. 1, pp. 447-455, 2011.

[19] C. Orha, A. Pop, C. Lazau, I. Grozescu, V. Tiponut, and F. Manea, "Silver doped natural and synthetic zeolites for removal of humic acid from water," Environmental Engineering and Management Journal, vol. 11, no. 3, pp. 641-649, 2012.

[20] A. Medina, P. Gamero, X. Querol et al., "Fly ash from a Mexican mineral coal I: mineralogical and chemical characterization," Journal of Hazardous Materials, vol. 181, no. 1-3, pp. 82-90, 2010.

[21] A. S. M. Junaid, M. M. Rahman, G. Rocha et al., "On the role of water in natural-zeolite-catalyzed cracking of athabasca oilsands bitumen," Energy \& Fuels, vol. 28, no. 5, pp. 3367-3376, 2014.

[22] K. V. Kumar, "Linear and non-linear regression analysis for the sorption kinetics of methylene blue onto activated carbon," Journal of Hazardous Materials, vol. 137, no. 3, pp. 1538-1544, 2006.

[23] V. E. Copcia, C. Luchian, S. Dunca, N. Bilba, and C. M. Hristodor, "Antibacterial activity of silver-modified natural clinoptilolite," Journal of Materials Science, vol. 46, no. 22, pp. 7121-7128, 2011.

[24] E. S. Dragan, M. V. Dinu, and D. Timpu, "Preparation and characterization of novel composites based on chitosan and clinoptilolite with enhanced adsorption properties for $\mathrm{Cu}^{2+}$," Bioresource Technology, vol. 101, no. 2, pp. 812-817, 2010. 

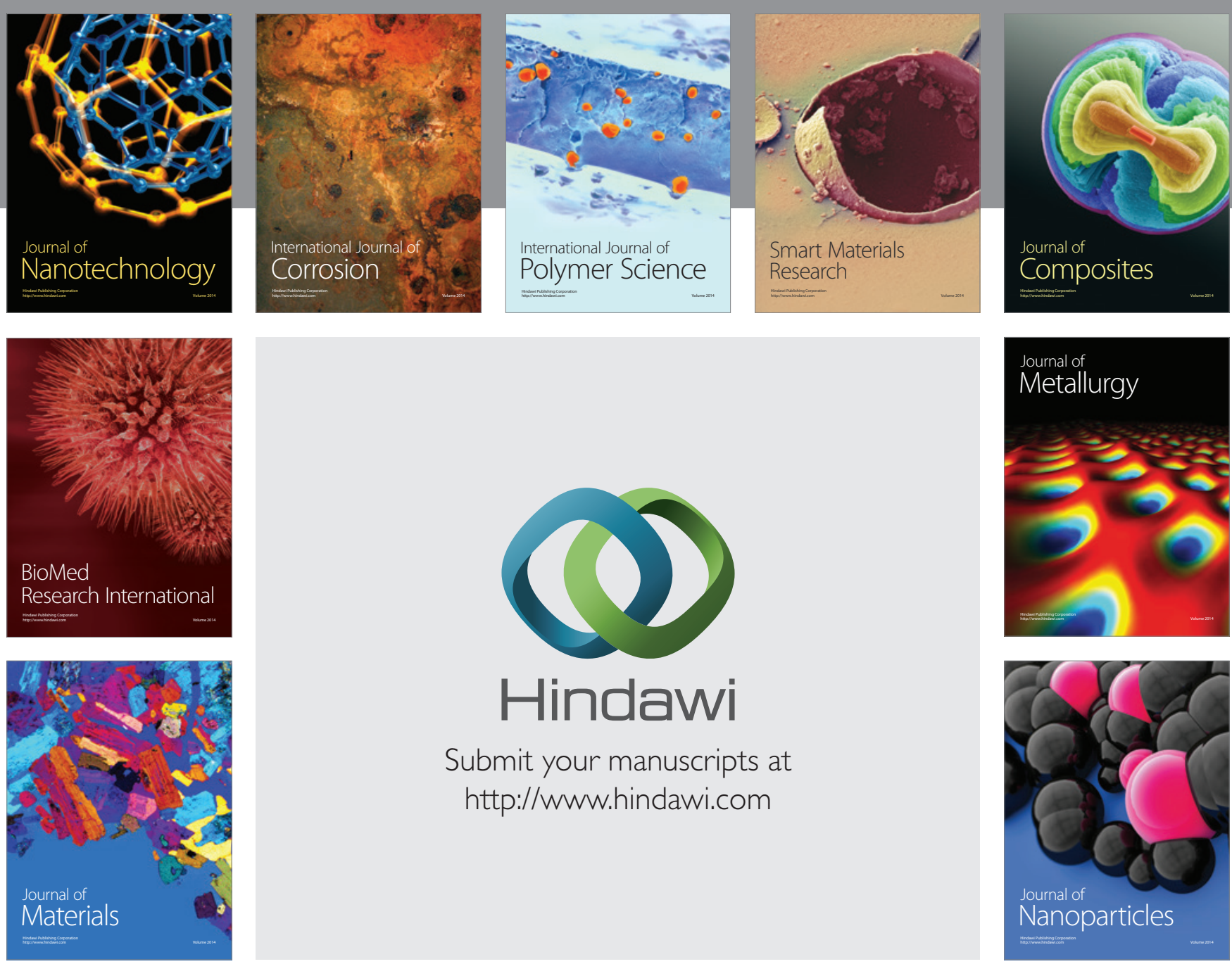

Submit your manuscripts at http://www.hindawi.com
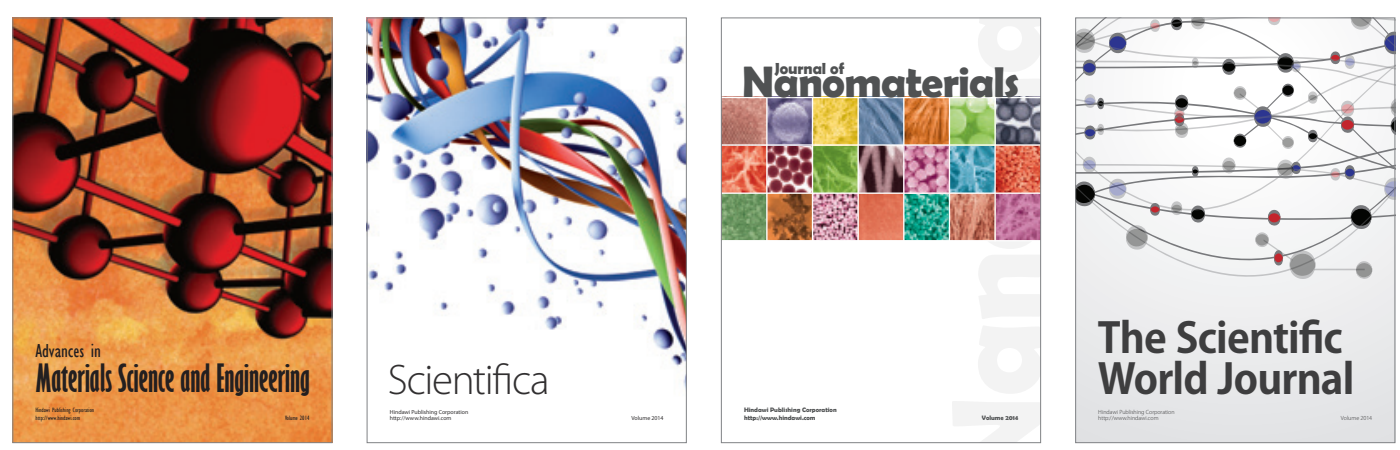

\section{The Scientific World Journal}
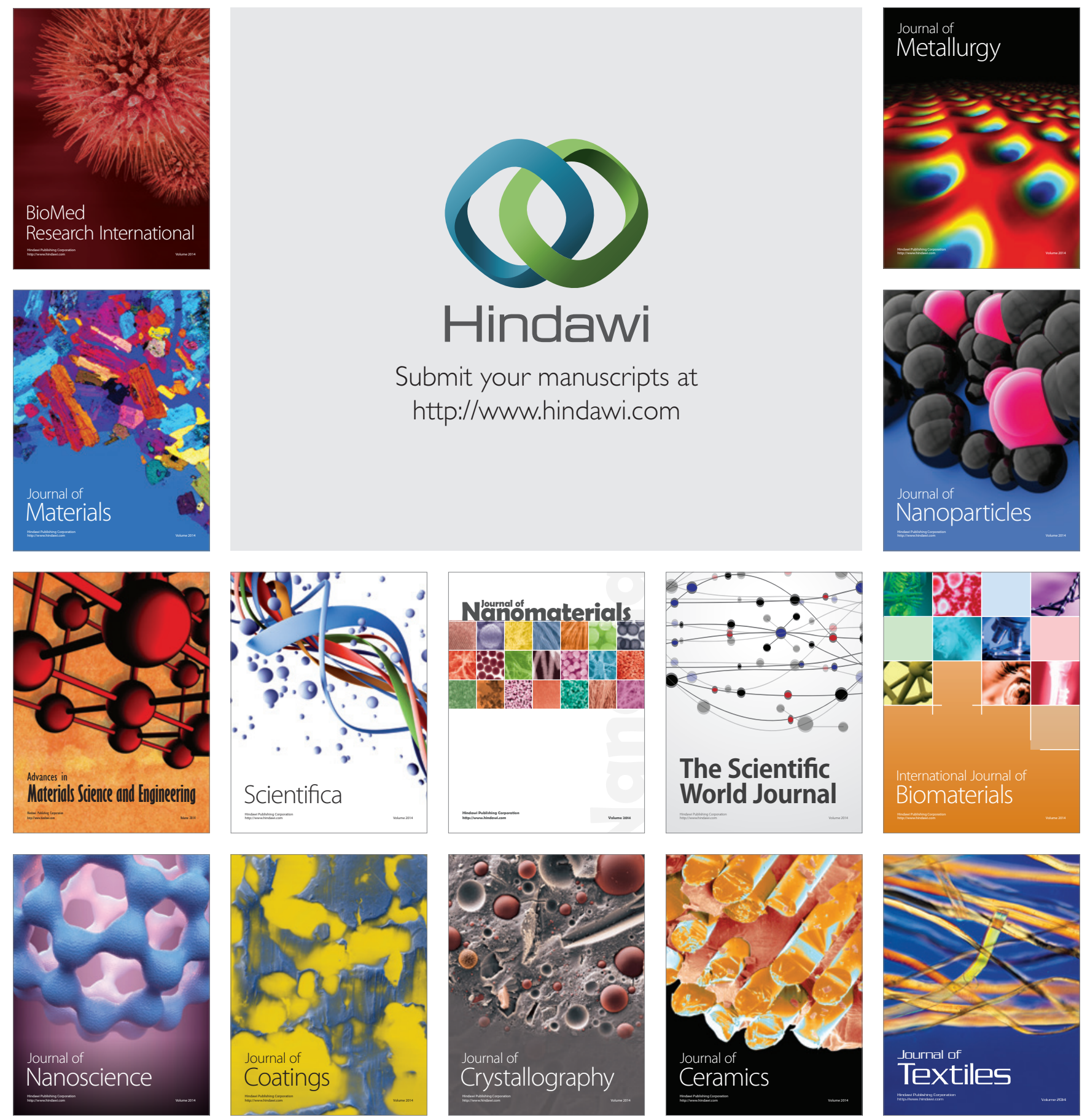